\title{
FATIGUE CRACK GROWTH OF AGE-HARDENED AI ALLOY UNDER ULTRASONIC LOADING
}

\author{
Q. CHEN \\ Department of Mechanical Engineering, Kochi National College of Technology \\ Nankoku, Kochi 783-8508, Japan \\ qchen@me.kochi-ct.ac.jp \\ N. KAWAGOISHI \\ Department of Mechanical Engineering, Faculty of Engineering, Kagoshima University \\ Kagoshima, Kagoshima 890-0065, Japan \\ hiro@mech.kagoshima-u.ac.jp \\ K. KARIYA \\ Department of Mechanical Engineering, Dai-ichi University \\ Kirishima, 899-4395, Japan \\ k-kariya@daiichi-koudai.ac.jp \\ Y. NU
}

Hubei Key Laboratory of Hydroelectric Machinery Design \& Maintenance, China Three Gorges University, Yichang, Hubei, China

yan_nu@ctgu.edu.cn

\section{GOTO}

Department of Mechanical Engineering, Oita University

Oita, 870-1192, Japan

masagoto@cc.oita-u.ac.jp

An age-hardened and extruded Al alloy 7075-T6 was fatigued under both ultrasonic loading $(20 \mathrm{kHz})$ and rotating bending $(50 \mathrm{~Hz})$ in the environments of controlled humidity, distilled water and oxygen gas respectively, to investigate the availability of ultrasonic fatigue test as a timesaving tool for the reliability evaluation of materials subjected to conventional frequency loading. Although fatigue strength decreased slightly at relative humidity below $60-70 \%$, it degraded significantly when the humidity was increased beyond that level, irrespective of the loading frequency. However, the mechanisms of strength degradation involved in high humidity are quite different. Under rotating bending, fatigue strength decreased because crack growth was accelerated due to brittle fracture, whileas the decrease in fatigue strength under ultrasonic loading was caused by crack propagation transition from tensile mode to shear mode cracking.

Keywords: Crack growth mode; extruded 7075-T6; environmental effects. 


\section{Introduction}

Al alloys have been widely used as engineering materials in many machines and structures because of their excellent properties such as high specific strength, high resistance to corrosion and easy to recycle. Especially, high strength Al alloys are effective to reduce environment load. However, fatigue strengths of high strength $\mathrm{Al}$ alloys are lower than those expected by their high static strengths and sensitive to corrosive environment even in mild atmosphere. ${ }^{1}$ Moreover, they have no definite fatigue limit. Therefore, it is important to know the fatigue strength of high strength Al alloys in corrosive environment and in the long life region beyond $10^{7}$ cycles to ensure the strength integrity for long-term service. However, fatigue test over $10^{7}$ cycles is a time consuming task that will take days and months. Ultrasonic fatigue test is one of attractive methods in terms of time saving, though there are many problems such as the effects of loading frequency and environmental conditions on fatigue strength to be clarified. ${ }^{2}$

In the present study, in order to investigate the applicability of ultrasonic fatigue test for the evaluation of fatigue properties of $\mathrm{Al}$ alloy under conventional loading frequency, fatigue tests under both ultrasonic frequency $(20 \mathrm{kHz})$ and rotating bending $(50 \mathrm{~Hz})$ were carried out for an age-hardened Al alloy 7075-T6 in environments of controlled relative humidity, distilled water and oxygen gas.

\section{Material and Experimental Procedures}

Material used was an extruded bar of an age-hardened Al-Zn-Mg-Cu alloy (7075-T6). The material as received was $22 \mathrm{~mm}$ in diameter with a mean grain size of about $8 \mu \mathrm{m}$. The chemical composition (wt. \%) of the alloy was $0.09 \mathrm{Si}, 1.47 \mathrm{Cu}, 0.25 \mathrm{Fe}, 0.03 \mathrm{Mn}$, $2.56 \mathrm{Mg}, 0.19 \mathrm{Cr}, 5.46 \mathrm{Zn}, 0.03 \mathrm{Zr}, 0.03 \mathrm{Ti}$, and the remainder Al. The mechanical properties of the alloy were $639 \mathrm{MPa}$ of $0.2 \%$ proof stress, $691 \mathrm{MPa}$ of tensile strength, $764 \mathrm{MPa}$ of true fracture strength and $9.5 \%$ of reduction of area, respectively. Fatigue tests were carried out using a piezoelectricity actuated ultrasonic machine and an Onotype rotating bending machine operated at $20 \mathrm{kHz}$ and $50 \mathrm{~Hz}$ in the different moisture conditions of $25,50,65,75$ and $85 \%$ relative humidity $(\mathrm{RH})$ as well as in distilled water. Some tests were carried out in oxygen $\left(\mathrm{O}_{2}:>99.5 \%, \mathrm{~N}_{2}:<0.5 \%, \mathrm{H}_{2} \mathrm{O}:<0.01 \mathrm{ppm}\right)$ gas to clear the effect of water vapor in ambient air. In case of ultrasonic fatigue, pulse-pause testing was performed with a pulse length of $1 \mathrm{~s}$ and pause time of $5 \mathrm{~s}$ to reduce possible temperature rise in the specimens induced under high frequency cycling. The observation of fatigue damage and the measurement of crack length were conducted under a scanning electron microscope (SEM) directly or under an optical microscope by using the plastic replication technique. Surface crack length, $l$, was measured in the circumferential direction. For more details see Ref. 3.

\section{Results and Discussions}

Figure 1 shows $S-N$ curves of the alloy tested under ultrasonic cycling in all of the above described environments. Although the effect of humidity on fatigue strength is relatively 
small in the humidity below $50 \%$, fatigue strength is largely decreased in the higher humidity above $65 \%$, especially in the long life region beyond $10^{7}$ cycles. These results are very important, because humidity in ambient air can vary normally from $25 \%$ to $85 \%$ in practical use.

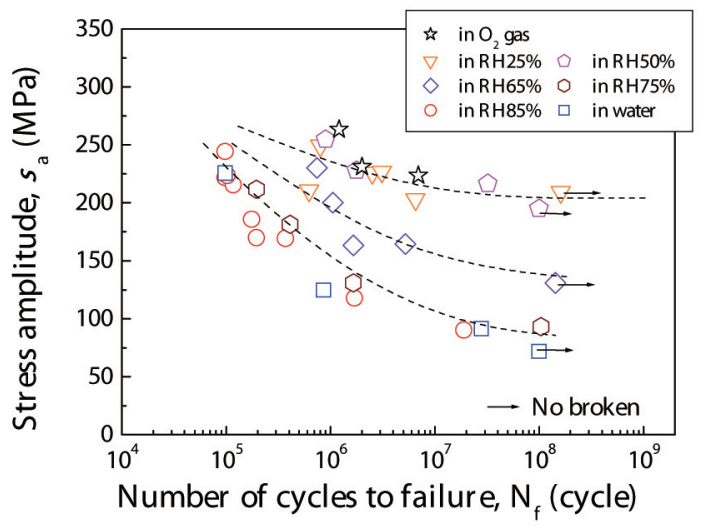

Fig. 1. $S$ - $N$ curves under ultrasonic fatigue.

Similar effect of humidity on the fatigue strength of the alloy was found in rotating bending fatigue too, as shown in Fig. 2. In Fig. 2, the results obtained under ultrasonic fatigue are indicated by dotted lines for comparison. Fatigue strength is higher under ultrasonic fatigue than under rotating bending in low humidity, though it is lower in high humidity. That means that the decreasing rate of fatigue strength by high humidity is larger under ultrasonic loading than under rotating bending, which is inverse from the point of view of corrosion fatigue which is a time dependent damage, because loading time for a specific fatigue life is shorter in ultrasonic loading than in rotating bending.

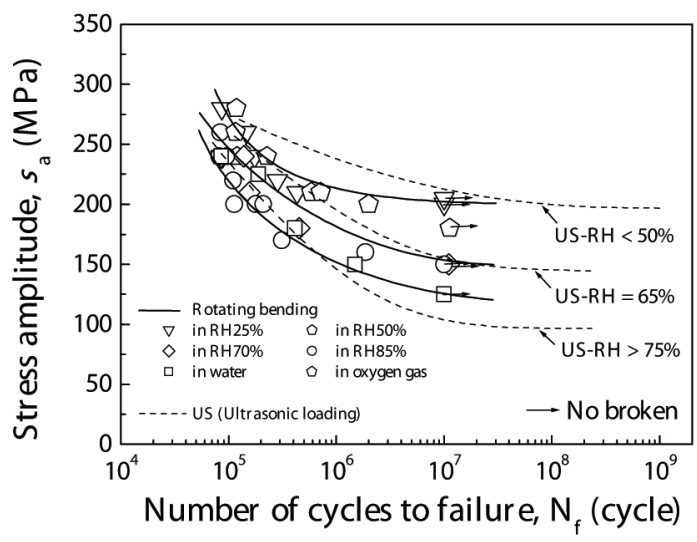

Fig. 2. $S$ - $N$ curves under rotating bending fatigue. 
Figure 3 shows the significant environmental effect on fatigue strength defined by fatigue strength at $10^{7}$ cycles. Figure 4 is typical morphologies of cracks showing the effects of both humidity and loading frequency. The growth direction of cracks changes from a tensile mode to a shear one macroscopically under ultrasonic loading, though the tensile mode cracks were rarely observed in high humidity, implying that transition in crack growth mode may be related to water molecules at crack tips. Meanwhile, multi shear mode cracks initiated and then coalesced in high humidity. In case of rotating bending fatigue, however, cracks propagate merely in tensile mode and the effect of high humidity on crack morphology was not recognized.

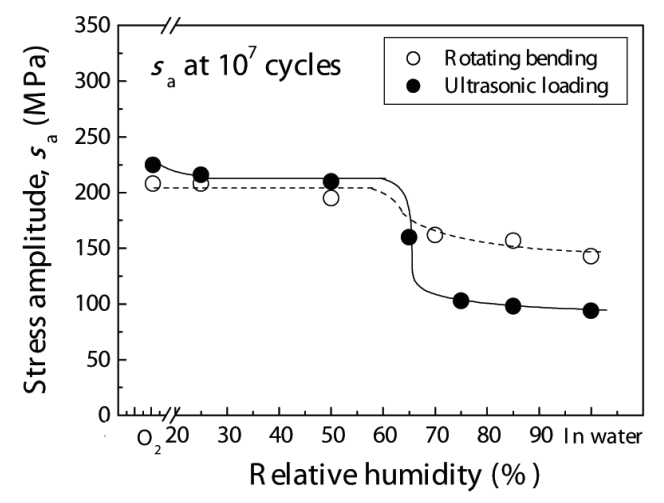

Fig. 3. Environmental dependence of fatigue strength defined at $10^{7}$ cycles.

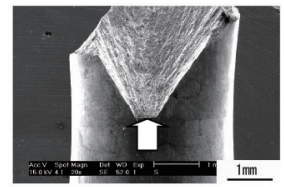

(a-1) In RH 25\% $\left(s_{\mathrm{a}}=249 \mathrm{MPa}, \mathrm{N}_{\mathrm{f}}=7.99 \times 10^{5}\right.$ cycles $)$

\section{(a) UItrasonic loading}

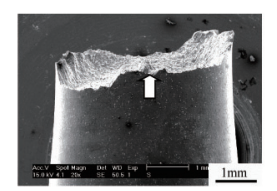

(b-1) In RH $25 \%$ $\left(s_{\mathrm{a}}=240 \mathrm{MPa}, \mathrm{N}_{\mathrm{f}}=8.78 \times 10^{4}\right.$ cycles $)$

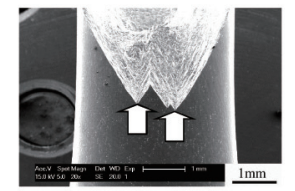

(a-2) In RH 65\%

( $s_{\mathrm{a}}=230 \mathrm{MPa}, \mathrm{N}_{\mathrm{f}}=7.41 \times 10^{5}$ cycles)

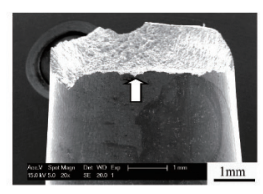

$\left(s_{\mathrm{a}}=210 \mathrm{MPa}, \mathrm{N}_{\mathrm{f}}=1.56 \times 10^{5}\right.$ cycles $)$ (b-2) In RH 70\%

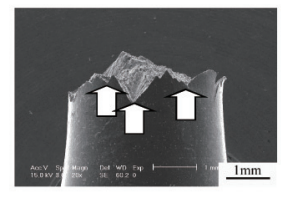

(a-3) In RH 85\%

( $s_{\mathrm{a}}=221 \mathrm{MPa}, \mathrm{N}_{\mathrm{f}}=9.75 \times 10^{4}$ cycles)

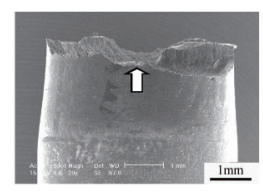

(b-3) In RH 85\% ( $s_{\mathrm{a}}=260 \mathrm{MPa}, \mathrm{N}_{\mathrm{f}}=8.40 \times 10^{4}$ cycles)

(b) Rotating bending

Fig. 4. SEM micrographs showing crack morphologies observed in (a) ultrasonic and (b) rotating fatigue. 
It was found that both the initiation and propagation of a crack are accelerated by high humidity. The angle of the growth direction of shear mode cracks to the stress axis was nearly constant of $35^{\circ}$, which suggests that the change in the crack growth mode be related to the marked texture of the alloy on (111) plane due to strong extrusion work. Further observation of etch pit pattern formed on the fracture surface of the shear mode cracks realized that these shear mode cracks propagated primarily on (100) planes. The

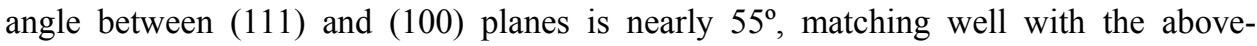
mentioned constant angle of $35^{\circ}$, which supports that the crack growth mode transition is related to the marked texture of the alloy. Meanwhile, fatigue tests in oxygen gas and in water disclosed that there was much debris on fracture surfaces tested in water, though little debris was observed on fracture surfaces tested in oxygen gas. These results indicate that high humidity promotes crack initiation by anodic dissolution.

Figure 5 shows fracture surfaces in water under ultrasonic fatigue and rotating bending fatigue, respectively. In case of ultrasonic fatigue, many slip planes and voids are observed on fracture surface where a shear mode crack propagated in both low and high humidity environments, meaning that there is no difference in fracture mechanism caused by humidity. Therefore, the shear mode crack may be explained as a result that the absorption rates of water vapor at the crack tip are smaller than crack growth rate due to the high loading frequency. ${ }^{4}$ In case of rotating bending, however, many brittle facets are observed on the surface fractured in water, as reported in Refs. 5 and 6, showing that definite difference in fracture mechanism induced by humidity environment is recognized, though the surface fractured in oxygen gas was covered with striations.

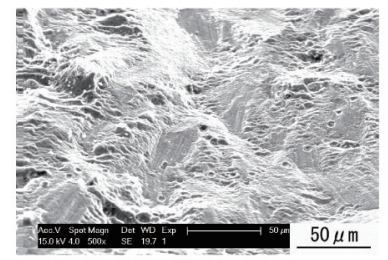

(a-1) $\ln 25 \%\left(s_{\mathrm{a}}=225 \mathrm{MPa}\right)$

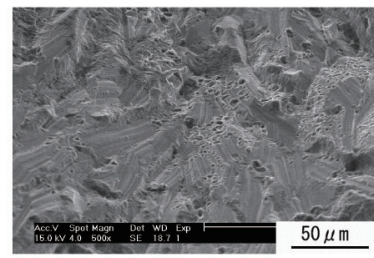

$(\mathrm{a}-2) \ln 85 \%\left(s_{\mathrm{a}}=221 \mathrm{MPa}\right)$

(a) Ultrasonic loading

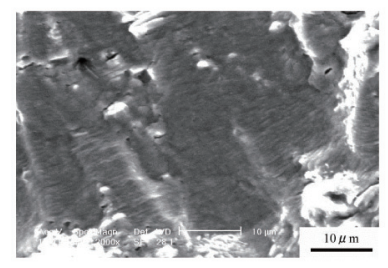

(b-1) $\ln 25 \%\left(s_{\mathrm{a}}=240 \mathrm{MPa}\right)$

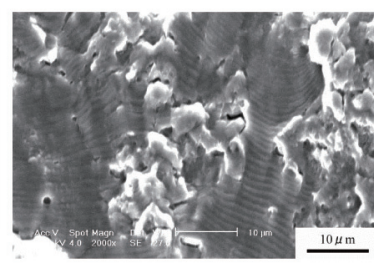

(b-2) In $85 \%\left(s_{\mathrm{a}}=240 \mathrm{MPa}\right)$

(b) Rotating bending

Fig. 5. SEM micrographs showing humidity effect in (a) ultrasonic and (b) rotating fatigue. 
From the results mentioned above, the decrease in fatigue strength by high humidity may be explained as follows: under ultrasonic loading, although high humidity does not affect the growth rate of the shear mode crack, it does promote crack initiation and change crack growth mode from steady tensile mode to catastrophic shear one so as to decrease fatigue strength tremendously, because most of fatigue life is occupied by the growth life of a shear mode crack. On the other hand, under rotating bending, the crack growth is accelerated by brittle fracture due to enhanced hydrogen embrittlement in high humidity, meaning that the main cause for the decrease in fatigue strength is the acceleration of both initiation and propagation of a crack.

\section{Conclusions}

The applicability of ultrasonic fatigue methodology for the evaluation of fatigue properties of Al alloy under conventional loading frequency was investigated. Fatigue tests under both ultrasonic frequency $(20 \mathrm{kHz})$ and rotating bending $(50 \mathrm{~Hz})$ were carried out for an extruded bar of an age-hardened Al alloy 7075-T6 in the controlled relative humidity of $25,50,65,75$ and $85 \%$ respectively, in addition to distilled water and oxygen gas. Although fatigue strength decreased slightly at humidity below $60-70 \%$, significant degradation occurred above that level of humidity, irrespective of the loading frequency. However, the degradation mechanisms by high humidity involved in both testing methods are different. Fatigue strength under rotating bending was decreased by the acceleration of initiation and growth of a crack due to brittle fracture, while the decrease in fatigue strength under ultrasonic cycling was caused by the transition from a tensile mode to a shear mode cracking in addition to the promotion of crack initiation by anodic dissolution.

\section{Acknowledgments}

The authors would like to acknowledge to Mr. T. Fukudome for his generous support on experiment.

\section{References}

1. K. Endo and K. Komai, Trans. Jpn Soc. Mech. Eng., 29, 162-167 (1980).

2. N. Kawagoishi, J. Ogawa, Q. Chen, M. Goto and K. Morino, Trans. Jpn Soc. Mech. Eng. 72, 1542-1549 (2006).

3. Q. Chen, N. Kawagoishi, M. Oki, M. Goto and Q.Y. Wang, J. Solid Mech. Mater. Eng., 2, 1399-1409 (2008).

4. N. Kawagoishi, T. Fukudome, Y. Nakamura, Y. Ohzono and M. Goto, Trans. Jpn Soc. Mech. Eng. 76, pp.938-946 (2010).

5. T. Broom, and A. Nicholson, J. Inst. Metals, 89, 183-190 (1961).

6. R.E. Ricker and D.J. Duquette, Metall. Trans. A, 19A, 1775-1783 (1988). 